\title{
A SEMIÓTICA DA NARRATIVA NA TELEDRAMATURGIA: O NÍVEL NARRATIVO EM A FAVORITA
}

\section{THE SEMIOTICS OF NARRATIVE IN TELEDRAMATURGY: THE NARRATIVE LEVEL IN A FAVORITA}

\author{
Mario Abel Bressan Junior \\ UNISUL - Universidade do Sul de Santa Catarina
}

\begin{abstract}
RESUMO: São poucas as pesquisas em relação à Semiótica da Narrativa aplicadas à teledramaturgia, por isso optou-se por essa temática na presente investigação. Na telenovela, as personagens desempenham funções importantes para o desencadeamento da narrativa, movendo as ações e construindo um processo de significação necessário para o entendimento da história. A semiótica da narrativa contribui para o entendimento neste processo de significação. Nela são identificados os níveis, Fundamental, Narrativo e Discursivo, responsáveis pelo percurso gerativo de sentido na narração. Diante disso, este estudo apresenta, com base no nível narrativo da semiótica da narrativa, descrito por Algirdas Julien Greimas, o sentido produzido pelas personagens Flora e Donatela, da telenovela A Favorita, exibida pela Rede Globo no ano de 2008. Após o estudo bibliográfico e descritivo realizado, tornou-se possível perceber que, diante das significações produzidas pela personagem Flora, o telespectador entendia que ela estava falando a verdade e era a heroína da história, fato que é revertido após a revelação da verdadeira assassina.
\end{abstract}

PALAVRAS-CHAVE: Telenovela; Semiótica da narrativa; Greimas; A Favorita.

ABSTRACT: There have been few researches which have dealt with the semiotics of the narrative for the study of teledramaturgy. Thus, this theme was chosen for the present research. In a soap opera, the characters have important roles which contribute to the development of the narrative, move the actions and build a process of signification required to understand the story. The semiotics of narrative contributes to understanding this process of signification. The semiotics of narrative consists of the following levels: fundamental, narrative and discursive which are responsible for the generative route of meaning in narration. Thus, based on the narrative levels of the semiotics of narrative, described by Algirdas Julien Greimas, the aim of this study is to show the structures of the meanings produced by the characters Flora and Donatela in the soap opera A Favorita (The Favorite), broadcasted by Globo Television Network in 2008. The bibliographic and descriptive studies show that the meanings produced by the character Flora made the viewers to believe that she was telling the truth and was the heroine of the story, a fact that is reversed after the revelation of the true killer.

KEYWORDS: Soap opera; Semiotics of narrative; Greimas; The Favorite. 


\section{INTRODUÇÃO}

A telenovela é um produto forte e influente da televisão brasileira, promovendo estereótipos por meio das suas personagens, lançando jargões, e apresentando-se como um produto altamente rentável. A importância desempenhada pela personagem não se restringe aos escritos do autor. Um exemplo disso são as personagens das telenovelas que sobrevivem no imaginário dos telespectadores, muitas vezes tempos depois de seu término.

Nas telenovelas, o contexto estrutural é formado desde a sinopse elaborada pelo autor até o desenvolvimento de um roteiro. Posteriormente, atores e atrizes desempenham papéis (personagens) para dar vida a este tipo de narrativa. É uma narrativa visual e sonora, composta por imagens e sons, capaz de nortear e direcionar o entendimento apropriado do telespectador para que então se possa acompanhar a história. O narrador é a lente da câmera. É pela tela da televisão que se conta o que a personagem está pensando ou fazendo nas cenas em que não existe o diálogo com outra personagem.

As personagens, em sua composição, carregam consigo elementos plausíveis de identificação, podendo ser a maneira de agir, de falar, de se vestir e de se portar diante dos acontecimentos que movimentam a narrativa. Tais elementos proporcionam um percurso de significação essencial para a construção da história. Isto acontece com maior intensidade em narrativas que possuem como trama central o suspense, ou um crime, no qual o telespectador não conhece o assassino ou do vilão da história. O que é apresentado a ele são indícios que são interpretados por meio dos sinais expostos pelo autor da ficção através da movimentação das personagens. A telenovela faz o telespectador pensar na narrativa apresentada, inserindose na trama como agente ativo, capaz de arriscar palpites.

É neste processo de significação e interpretação das personagens que surge a presente pesquisa, tendo como objeto de investigação as personagens Flora e Donatela, da telenovela A Favorita, de João Emanuel Carneiro, ambas suspeitas de um assassinato. $\mathrm{O}$ telespectador foi guiado pelas características das duas personagens, ao mesmo tempo em que "sofreu" um efeito de sentido provocado pelas ações das mesmas. Por isso, este artigo busca responder: Qual o sentido produzido pelas duas personagens? A resposta para esta questão foi buscada na semiótica da narrativa, analisando as personagens Flora e Donatela sob o viés do nível narrativo proposto por Algirdas Julien Greimas, verificando os efeitos de sentido produzidos pelas actantes ${ }^{1}$ em relação aos objetos de valor, estados de sujeito e agentes transformadores.

Acredita-se que esta investigação favorecerá o conhecimento sobre o percurso gerativo de sentido, em especial no Nível Narrativo, proposto pela Semiótica da Narrativa, visando uma abordagem importante e original, visto que há poucas pesquisas relacionadas ao assunto aplicadas em uma telenovela. Certamente, é uma leitura interessante para os estudiosos e apreciadores deste produto cultural que, apesar de ser também criado em outros países, projeta o Brasil como líder no cenário mundial.

\footnotetext{
${ }^{1}$ Greimas e Courtés sintetizam que o actante é aquele que provém da realização de algo. É “aquele que realiza ou sofre o ato". (1979, p.12).
} 


\section{O NÍVEL NARRATIVO NA ESCOLHA DA PERSONAGEM "FAVORITA"}

A narrativa, segundo a definição de Everaert-Desmedt (1984), é a representação, a interpretação de algo, de um acontecimento. Estes acontecimentos são retratados por ações das personagens que fazem parte da narrativa, da construção e da movimentação que elas realizam diante do percurso dos fatos. A autora ainda descreve que o acontecimento é a transformação, a passagem de um estado S para um estado S'.

Eco (1991) menciona Greimas, para quem a semiótica constitui um processo de significação e não só uma teoria de signos. Tal processo de significação é formado pelas estruturas actanciais e níveis que compõem o processo gerativo de sentido. Já na obra de Rector, Greimas afirma que o signo constitui uma estrutura superficial. Para ele "somente por meio de sua desestruturação (do signo) chegamos à significação, que lhe é subjacente". (GREIMAS apud RECTOR, 1978, p. 26).

Em todas as manifestações da linguagem ocorre um processo significativo, não vinculado ao signo singular. Rector (1978) destaca que, para Greimas, o objeto da semiótica não é o signo em si, e sim o estudo dos sistemas semióticos, neste caso o processo da significação. Estas manifestações de sentido reforçam a análise semiótica de uma narrativa. Segundo afirmação de Barthes (2008), a narrativa é um processo de linguagem e com isto produtora de sentidos. Por este motivo torna-se importante entender e compreender a origem e os procedimentos teóricos da significação nos textos narrativos.

O percurso gerativo de sentido postulado por Greimas (1976a) é composto por três instâncias ou níveis distintos: o Nível Fundamental, o Nível Narrativo e o Nível Discursivo. Sendo assim, ele é constituído pelas abstrações do leitor, ou telespectador, a partir da superfície do texto, e vai crescendo, constituindo-se em um simulacro organizado por normas, visando à compreensão. (FIORIN, 1999).

O que ocorre no Nível Narrativo, destaca Fiorin (1999), é a transformação do estado dos sujeitos. É neste nível que são manifestados os agentes transformadores de cada sujeito inserido na narrativa, como eles são apresentados no início da história e como acabam se modificando.

No Nível Narrativo verifica-se a aplicação e análise dos actantes da narrativa, o estado de ser e fazer dos sujeitos, e as suas relações com os objetos de valores, destinador e destinatário. Nos primeiros capítulos da história, Flora e Donatela são os principais actantes. Não os únicos, mas são eles que estruturam a narrativa. Greimas e Courtés (1979) explicam que os actantes são aqueles que realizam ou sofrem o ato, podendo ser seres, coisas e até mesmo figurantes, mas que participam do processo narrativo. Por isso, as outras personagens envolvidas são também actantes que irão contribuir para o processo de significação e construção da história. Isto fica claro nos primeiros capítulos, quando o telespectador não sabe ao certo quem está dizendo a verdade. Escolhe a sua favorita por indícios que são articulados pelas duas personagens centrais e também pelas que as rodeiam.

Rector (1978) afirma que os actantes exercem algumas funções que estruturam a construção da narrativa, substituindo assim, na visão de Greimas, o termo personagem. $\mathrm{O}$ actante é mais amplo, pode exercer várias funções. Para ela, estes papéis actanciais são constituídos em Sujeito, Objeto, Destinador, Destinatário, Adjuvante e Oponente, todos interligados e complementando a sequência da narração.

Conforme Greimas, o sujeito e o objeto na narrativa encontram-se no eixo do desejo. Todo sujeito na história buscará um objeto. É como destaca Everaert-Desmedt (1984): é na busca do sujeito pelo objeto que se dará a situação inicial e final da história. 
Nos primeiros sete capítulos de A Favorita o objeto de desejo de Donatela é se livrar de Flora, que acabou de sair da prisão após ter cumprido pena pelo assassinato de Marcelo Fontini, marido de Donatela. Este anseio de manter Flora afastada da família Fontini é apresentado nas cenas em que Donatela diz ter medo de Flora, fica irritada com a possível presença dela, e expressa em suas ações o desejo de afastá-la de todos. Donatela age com o intuito de distanciar Flora e forjar situações para que ela precise de ajuda financeira e, assim, acabe ficando longe da sua família.

Flora manifesta, logo em um momento inicial, o seu objeto de desejo: provar a sua inocência e desmascarar Donatela, acusada por Flora de ser a verdadeira assassina. Outro objeto de desejo de Flora aparece a partir do quarto capítulo: a aproximação com Lara, sua filha biológica com Marcelo, que fora criada por Donatela. Para isso, procura Irene, a mãe de Marcelo Fontini, e diz que não foi ela quem matou Marcelo, e sim Donatela. Quando ganha a confiança de Irene, diz querer ver Lara. Ela consegue quando Lara faz aniversário e Donatela organiza uma grande festa. Olhando de longe, Flora se emociona e então declara à Irene que Donatela havia lhe tirado tudo.

Nesta relação, de acordo com Greimas (1976a), há um investimento semântico denominado desejo de algo entre o sujeito e o objeto. Este desejo é estruturado pela relação em comum entre as duas personagens. Existe da parte de cada uma delas uma postura de afirmação, de provar a justiça, de integridade a ser provada.

O telespectador, ao identificar o desejo de ambas, passa a dar mais valor ao de Flora, pois o objeto da personagem se aproxima mais da moralidade e dos sentimentos de fácil aceitação do público. O que Flora almeja é provar que ela não é assassina, e recuperar o que perdeu, principalmente o amor de Lara. Donatela, ao contrário, para conseguir o seu objeto, demonstra a todos o medo que tem de Flora e oferece dinheiro para ela ir embora, entre outras ações que são consideradas imorais e ilícitas pelo telespectador.

Percebe-se assim que as personagens sujeito aqui observadas encontram-se uma, de posse de seu objeto, e a outra, afastada dele. Donatela mantém a posse de seu objeto, pois todos estão afastados de Flora. Ela só não consegue fazer com que Flora saia da cidade, mas a mantém afastada dos Fontini. Flora, no entanto, mostra-se longe de seu objeto. Ela não consegue provar a sua inocência e nas primeiras cenas nenhuma outra personagem acredita nela. Flora está em disjunção com o seu objeto e isto geralmente acontece no início das histórias. Donatela apresenta-se em conjunção com ele. As palavras de Everaert-Desmedt (1984), afirmam que o sujeito, quando está de posse do seu objeto, está em uma relação de conjunção; ao contrário, quando o sujeito não possui o objeto, encontra-se em um estado de disjunção.

Dentro da semiótica da narrativa, é esta relação de conjunção e disjunção do sujeito em relação ao objeto que sustenta a narratividade, isto é, são as transformações de estado que fundamentam a narrativa, sendo este movimento essencial para o processo de significação. Há dois tipos de enunciados elementares na sintaxe da narrativa, denominados enunciados narrativos, que Everaert-Desmedt (1984) classifica em enunciados de estado (ser) e enunciados de fazer (ação). No início da telenovela A Favorita podem ser visualizados os enunciados de estado das personagens Donatela e Flora.

Todas as ações de Donatela não a impediram de transformar o seu estado de conjunto para disjunto. Flora, entretanto, após a insistência em reafirmar para Irene as suas razões, alcança parte de seu objeto. Ela passa de um estado para o outro devido ao seu fazer.

Everaert-Desmedt (1984) observa que, geralmente, nas narrativas há a figura do anti-sujeito. Para a autora, essa relação nasce quando um sujeito precisa se opor ao outro para conseguir o que deseja. Isto é bem visível em A Favorita. Donatela precisa se opor à 
Flora para conseguir o seu objeto. O mesmo acontece com Flora: ela precisa estar em uma situação de oponência para a conquista de seu objeto. Para o telespectador, as duas podem ser tanto sujeitos quanto anti-sujeitos, isto ainda no referente aos primeiros capítulos.

Quanto à organização dos agentes transformadores dos sujeitos nos Programas Narrativos defendidos por Everaert-Desmedt (1984), eles compreendem quatro fases: a manipulação, a competência, a performance e a sanção. Estas etapas correspondem às ações do sujeito em buscar o seu objeto, e às consequências por ele sofridas.

A manipulação, segundo Fiorin (1999), leva um sujeito a manifestar um querer e/ou um dever, lembrando que o querer, o dever, o poder e o saber são os objetos modais identificados por Greimas. Ainda para Fiorin, os sujeitos, antes de obter o seus objetos de valor, expõem a sua vontade de querer, dever, poder ou saber. Em A Favorita, por exemplo, ambas as personagens, antes de conseguirem o seu objeto de valor, demonstram querer este objeto. Deixam isto claro para o telespectador. Depois, o dever também é "visível" na busca do objeto de valor. Donatela, por exemplo, diz que todos devem ficar longe de Flora por ela ser uma mulher perigosa e por estar armando alguma coisa contra eles. Flora, por sua vez, demonstra que deve provar a sua inocência e conquistar o amor de Lara.

Na observação de Fiorin (1999), o sujeito pode manipular por provocação, por intimidação, tentação e sedução. Em relação às duas personagens, aparecem o querer e o dever de Flora na manipulação para alcançar o próprio objeto de valor. Para ilustrar a manipulação, usa-se como exemplo uma das cenas em que Flora procura Irene e conta a versão dela. Relata que conheceu Donatela quando ainda eram pequenas e ficaram amigas. Pedro, o pai de Flora, criara Donatela, que havia perdido os pais em um acidente. As duas sempre gostaram de cantar e começaram a fazer isso algum tempo depois de se conhecerem, apresentando-se em festas e outras ocasiões. Em um destes shows conheceram Marcelo. Flora afirma que Donatela roubou-o no primeiro encontro, porque era ambiciosa e seu sonho era casar-se com um homem rico.

Após esta exposição de Flora, Irene alega estar cheia de dúvidas. Flora alerta que se ela tem dúvida é porque acredita no que Flora vem afirmando. Então pede para ver a filha que faz aniversário neste dia.

No primeiro momento Irene nega, afirmando que a assassina de seu filho não vai pisar na sua casa novamente. Mas Flora se defende, argumenta, e convence Irene a levála para observar Lara de longe.

No diálogo acima, fica evidente a manipulação de Flora para conquistar o seu objeto. Ela demonstra o querer e o dever. Através da súplica, da insistência e da sua versão sobre os fatos, convence Irene e consegue o que quer.

A manipulação de Donatela vem por meio de ordens e exigências. Ordena que todos fiquem longe de Flora. A sua justificativa é de que aquela é capaz de fazer muito mal. Para o telespectador, fica mais convincente a manipulação de Flora, por apresentar argumentos e fatos mais consistentes.

É pela competência e pela performance que é demonstrado o saber e o poder do sujeito em relação ao objeto. Na manipulação, ele expõe o querer e o dever, enquanto que nesta fase o sujeito usa da competência para realizar a ação transformadora de estado, que é visualizada na performance. Isto é, o sujeito, para desenvolver qualquer ação, para apresentar sua performance, necessitará de alguma competência. Greimas (1977) explica que, no plano narrativo, o poder-fazer e/ou o saber-fazer implica um desempenho por parte daquele que realiza a ação.

Flora apresenta sua performance para o telespectador por meio das falas com Irene e pelo fato de procurar o pai e demonstrar carinho por ele. Everaert-Desmedt (1984) 
atesta que a performance acontece no fazer, no desempenho. A competência é observada pela capacidade do sujeito em desenvolver a ação. Pode-se dizer que Flora foi competente na sua performance porque utilizou-se de vários recursos para conquistar o objeto. Assegurou para Irene que Donatela e Dodi (atual marido de Donatela) estariam juntos, que seriam cúmplices e que Lara teria sido "a galinha dos ovos de ouro, o passaporte para a mansão dos Fontini". Ela sempre alegou ser inocente, chorou, mostrou-se uma pessoa simples, humilde, sempre falando em tons suaves, não alterando em nenhum momento a voz enquanto conversava com Irene e com o seu pai.

A performance de Donatela aconteceu pelas falas, ao solicitar que todos ficassem longe de Flora; e pelas ações que realizou, como a contratação de um detetive para seguir Flora com a intenção de saber o que a rival estaria fazendo, o contato com pessoas para roubarem o dinheiro de Flora para que ela pudesse aceitar sua oferta em dinheiro e ir para fora do país e a insistência para que Lara saísse do Brasil para afastá-la de Flora. Entretanto, apesar dessas ações, pode-se perceber que ela não demonstrou a competência necessária para conseguir o que queria.

O público da telenovela não esteve "ausente" neste período: percebeu a "superioridade" de Flora sobre Donatela. Em termos semióticos Flora apresentou maior competência que Donatela, conseguiu o que queria, passando de um estado de disjunção para conjunção; enquanto que Donatela, perdeu, passando de um estado conjunto para o disjunto. Isto remete ao processo pelo qual o telespectador transitou para escolher a sua favorita, para eleger quem estava falando a verdade. Talvez Flora, nessa fase, tenha sido mais apontada como a que "portava" a verdade, porque demonstrou bom desempenho e competência para o que queria, ao contrário de Donatela. Greimas (1977) afirma que o sujeito pode ser competente e desempenhante ao mesmo tempo, mas que pode desempenhar alguma função e não ter competência para isto.

Em relação à sanção, a recompensa ou o castigo para ambas as personagens diante de suas ações não são apresentadas nesta seção, pois a telenovela está apenas no início. Conforme declaração de Fiorin (1999), é na sanção que as mentiras são descobertas e os segredos são revelados. Como não há nada ainda descoberto nestes primeiros capítulos, não há definição dos destinos de cada personagem.

Tendo em vista as relações até aqui pontuadas a respeito do sujeito e do objeto, a partir deste momento será aplicado nesta análise o segundo eixo dos papéis actanciais da comunicação, proposto por Greimas, revelando na narrativa a articulação do destinador e do destinatário.

O sujeito passa a ser um destinador quando solicita ao destinatário uma função ou tarefa em relação ao seu objeto de valor. Referindo-se ao o objeto de valor das duas personagens, são percebidos como destinatários de Donatela o detetive que ela contrata para seguir Flora, os homens que pagam uma mulher para roubar Flora e também Seu Pedro, o pai biológico de Flora.

Em uma das cenas de A Favorita, Donatela procura Seu Pedro para saber como ele está. O mesmo aparenta estar triste, preocupado com Flora. Donatela então declara que o melhor seria Flora sair da cidade, ficar longe deles. Ele concorda. Donatela lhe presenteia com um aparelho de TV. Ele agradece, diz que Donatela já fez muito por ele, e com carinho, diz ser ela a filha do coração. Os dois se abraçam e ela alerta: "Agora a gente só tem que ensaiar para quando ela vier procurar o senhor, o que o senhor irá dizer." Pedro, nesta sequência, serve como um destinatário para Donatela, uma vez que esta solicita a ajuda dele para manter Flora afastada. É destinatário porque o destinador, neste caso Donatela, 
pede auxílio a ele. O que pode ser compreendido também como adjuvante, elemento do terceiro eixo do nível narrativo explicado a seguir.

Flora tem como destinatária Irene, que a ajuda no encontro com Lara, sendo a filha um dos seus objetos de valor. Courtés (1979) reforça a importância do destinador e do destinatário por estes apresentarem uma relação essencial com o objeto.

A mesma importância é atribuída aos adjuvantes e oponentes, que formam o terceiro eixo exposto por Greimas, o do poder. Rector (1978) define que o adjuvante é o actante que auxilia o sujeito a conseguir o seu objeto, e que o oponente faz o contrário, articula ações para prejudicar a busca de um sujeito.

Na primeira semana da história, Donatela é a oponente de Flora e tem como adjuvante Pedro. Donatela, sendo oponente, pratica algumas ações em oposição à Flora, causando dificuldades para esta conquistar o seu objeto.

Flora, por sua vez, tem como adjuvante Irene, que a auxilia na conquista do objeto, sendo também Irene a actante oponente de Donatela, visto que é ela quem aproxima Flora de Lara. Greimas e Courtés (1979) explicam que o adjuvante é aquele que auxilia de maneira positiva e que é representado por um ator diferente do sujeito do fazer. Já o oponente auxilia de forma negativa. E isso é observado na descrição acima: Irene não é o sujeito, mas realiza ações para que o sujeito Flora adquira o desejado. Isto faz com que, consequentemente, Donatela não permaneça de forma conjunta com o seu objeto, exibindo nela outro aspecto negativo. Ela é quem atrapalha o anseio da outra.

Ao finalizar as explanações referentes ao nível narrativo, percebe-se que ele contribui no percurso gerativo de sentido por pontuar a aplicação dos papéis actanciais sujeito, objeto, destinador, destinatário, adjuvante e oponente, revelando o processo de significação que corresponde à Flora e à Donatela.

Tornou-se possível observar, neste estudo, as leituras atribuídas à Flora e Donatela nos primeiros capítulos de A Favorita, verificando os elementos e os papéis actanciais propostos a cada uma pelo autor da história. Agrupando todos os itens observados até o momento, evidencia-se, em um olhar direcionado para o nível narrativo proposto por Greimas, que Flora pode estar falando a verdade, ter sido vítima de uma armação e ter sido presa por um crime que não cometeu.

\section{CONSIDERAÇÕES FINAIS}

Inseridas na realidade cultural brasileira, as telenovelas são capazes de produzir mudanças de comportamento, questionamentos da sociedade, desempenhando um papel ativo no processo de socialização do telespectador. É o compartilhamento de significados culturais, mostrando novos modos de viver e pensar, conforme comenta Straubhaar (2004). É por meio das telenovelas que o país é visto e relatado. (MARTIN-BARBERO; REY, 2001). Algumas delas são próximas da realidade, outras têm características fantasiosas, que instigam a curiosidade do público. É a transnacionalidade definida por Lopes (2004), que desperta a reflexão sobre os diversos sentidos que a história transmite no plano nacional. Sentidos estes são articulados com a presença das personagens de ficção.

Greimas (1977), por meio da elaboração de uma semiótica voltada para a narrativa, possibilitou a identificação dos papéis actanciais, o detalhamento da função do sujeito em relação ao seu objeto de valor, a visualização do estado do sujeito perante o objeto, e dos agentes de transformação do sujeito em relação ao seu objeto de valor: a manipulação, a competência e o desempenho para conseguir o que é almejado na história, e a sanção. Além de Greimas, outros autores puderam fornecer elementos de base a esta etapa da pesquisa, 
trilhando na sequência da significação da narrativa e complementando a percepção greimasiana.

Acredita-se que o presente trabalho possibilitou ao autor responder à indagação inicial, que consta na Introdução, e o objetivo a ela relacionado, uma vez que foi possível "posicionar" as personagens Flora e Donatela nos primeiros capítulos em relação ao nível narrativo explicado pela semiótica da narrativa, alcançando-se a percepção das estruturas de sentido por elas produzidas.

Um dos fatos que corroboraram para esta conclusão foi a amizade de Flora com Irene, sua adjuvante e destinatária. Irene era uma mulher "de classe", sábia, que despertava a credibilidade do público. $\mathrm{O}$ adjuvante e destinatário de Donatela era diferente: Pedro, seu pai de criação, era um homem doente, viciado em jogo, e maltratava Flora, sua filha biológica. Isto levou Irene várias vezes a suspeitar que Donatela havia "comprado" Pedro com dinheiro para alimentar o seu vício. O adjuvante de Flora nesta história estabeleceu um sentido importante: Irene convencia mais. Pedro, nem tanto. Este foi mais um sentido negativo atrelado à personagem Donatela.

Outra conclusão possível foi em relação ao objeto de valor das duas personagens. Donatela, com o anseio de ver Flora longe da sua vida e de sua família, expressava medo com a possibilidade de esta última se aproximar de Lara. O objeto de Flora era a luta por ser inocentada e pelo amor de sua filha. Objetos distintos, mas os de Flora convenciam muito mais, por estarem mais próximos da moralidade e dos sentimentos aceitos como verdadeiros.

Nos primeiros capítulos, o fato de Donatela estar em conjunção com o seu objeto, e de Flora estar em disjunção, também direciona um olhar significativo do público para quem poderia estar falando a verdade. Everaert-Desmedt (1984) observa que é na busca do objeto que acontece a ação da personagem. As narrativas iniciam com o sujeito na busca por determinado objeto. Talvez esta tenha sido a leitura do telespectador: Donatela já estava de posse do seu objeto e fazia mal à rival para manter-se neste estado. Já Flora buscava o seu objeto constantemente, com a sua insistência e perseverança.

Por meio da análise realizada, tornou-se possível perceber também que Flora foi muito mais competente nas suas ações do que Donatela. Manipulou e desempenhou suas ações com mais emoção para conseguir o seu objeto de valor. Donatela, no entanto, só o perdeu. Até o momento da revelação, esta só se distancia dele. Pelas suas ações, ela não consegue o que queria. O público visualizava Donatela sempre perdendo, afastando-se das pessoas que amava, mantendo a relação somente com Pedro.

Além de poder contribuir para o melhor entendimento das estruturas de sentido na teledramaturgia, a leitura deste artigo poderá ser bastante proveitosa para estudiosos do comportamento humano, como psicólogos; para pesquisadores do comportamento social e cultural, como sociólogos e educadores; para jornalistas, publicitários, escritores e linguistas; para acadêmicos destas áreas e de áreas afins; e finalmente, para todos os apreciadores de telenovelas e enredos de suspense, que venham a ser movidos por mera curiosidade.

\section{REFERÊNCIAS}

BARTHES, R. Introdução à análise estrutural da narrativa. In: BARTHES, R et al. Análise estrutural da narrativa: pesquisas semiológicas. 5. ed. Petrópolis: Vozes, 2008.

COURTÉS, J. Introdução à semiótica narrativa e discursiva. Coimbra (Portugal): Almedina, 1979. 
ECO, U. A estrutura ausente: introdução à pesquisa semiológica. 7. ed. São Paulo: Perspectiva, 1991.

EVERAERT-DESMEDT, N. Semiótica da narrativa: método e aplicações. Coimbra (Portugal): Livraria Almeida, 1984.

FIORIN, J. L. Sendas e veredas da semiótica narrativa e discursiva. Delta: documentação de estudos em linguística teórica e aplicada. São Paulo, v.15, n. 1, feb./july 1999. Disponível em: <http://www.scielo.br/scielo.php?script=sci_arttext\&pid=S0102-44501999000100009>.

Acesso em: 30 maio 2012.

GREIMAS, A. J. Semântica estrutural: pesquisa de método. São Paulo: Cultrix, 1976a. . Os atuantes, os atores e as figuras. In: CHABROL, Claude. Semiótica narrativa e textual. São Paulo: Cultrix, 1977.

GREIMAS, A. J; COURTÉS, J. Dicionário de semiótica. São Paulo: Cultrix, 1979.

LOPES, M. I. V. de. (Org.). Telenovela: internacionalização e interculturalidade. São Paulo: Loyola, 2004.

MARTÍN BARBERO, J; REY, G. Os exercícios do ver: hegemonia audiovisual e ficção televisiva. São Paulo: SENAC, 2001.

RECTOR, M. Para ler Greimas. Rio de Janeiro: F. Alves, 1978.

STRAUBHAAR, J. As múltiplas proximidades das telenovelas e das audiências. In: LOPES, Maria Immacolata Vassallo de. (Org.). Telenovela: internacionalização e interculturalidade. São Paulo: Loyola, 2004. 